\title{
From Legal Pluralism to Public Justification
}

\author{
Emmanuel Melissaris*
}

\begin{abstract}
The paper offers an argument for a conception of legal pluralism, which has some substantive upshots and at least partly alleviates that legal pluralism may regress to rampant relativism. In particular, I will argue that law in its pluralist conception is inextricably linked to the requirement of public justification. This is not by way of appealing to any transcendental normative ideals but as a matter of entailment of the very practice of law. But, perhaps to the disappointment of many, this procedural requirement is the only practical consequence of the concept of law. For thicker, substantive limits to what law can do and for ways in which legal pluralism may be reduced in real contexts one will have to turn to the actual circumstances furnishing the law with content and a different kind of thinking about the law.
\end{abstract}

Keywords: legal pluralism, diversity and law, law and justification, concept of law

\section{Introduction}

Theories of legal pluralism often find themselves in a bind. Some take the observer perspective and simply record the fact of legal pluralism remaining quiet on the substantive question of normative interrelations between various legal orders. This approach is open to the critique, already familiar from non-pluralist legal theoretical debates, that they have nothing interesting to say about law because they fail to appreciate law's practical character. When not accused of quietism, legal pluralist theory is accused of radical scepticism about value, precisely because it offers no way of adjudicating between diverse legal orders or of evaluating the content of any one of them. In response to that type of critique, some legal pluralism theorists have appealed to contextindependent meta-law to order the legal universe. This, however, is a slippery slope because it carries the opposite risk of undermining the very foundational claim that law is plural.

\footnotetext{
Associate Professor of Law, Law Department, London School of Economics and Political Science. I am grateful to Sanne Taekema and Wibo van Rossum as well as the two anonymous referees for their helpful critical comments. A version of this paper was presented at the School of Law, Queen Mary University of London. I am indebted to all the participants in that seminar and particularly to Roger Cotterrell, Ann Mumford, Maskymilian del Mar, Prakash Shah, Valsamis Mitsilegas, Wayne Morrison, Michael Lobban, Richard Nobles and David Schiff. Many thanks also to Sean Coyle, George Pavlakos, Alexis Galan Avila and Mariano Croce for their valuable comments on earlier drafts of the paper. I am solely responsible for all remaining errors.
}

In this article, I will argue that there is one conception of legal pluralism, which can avoid that bind. In particular, I will argue that law in that pluralist conception is inextricably linked to the requirement of public justification. This link is established not by appeal to some transcendental normative ideals but as an entailment of the very practice of law. Nevertheless, and perhaps to the disappointment of many, this procedural requirement is the only practical consequence of the concept of law. For thicker, substantive limits to what law can do and for ways in which legal pluralism may be reduced in real contexts one will have to turn to the actual circumstances furnishing the law with content and engage in a different kind of enquiry.

\section{A Pluralist Conception of Law}

Legal pluralism is generally considered to be an issue of early modernity ${ }^{1}$ as well as a problem of the late modern condition of globalisation. The difference between these two manifestations relates to the transformations of the role of the state. In early modernity the state assumed authority over large territories and populations, including many disparate communities, which had until then maintained their own, decentralised ways of governing their affairs and continued to adhere to their normative practices despite the establishment of central state authority. At that stage, legal pluralism is seen as a problem of 'too little law' in the sense that the state imposes its authority on all these other legal orders. In the globalised world this authority of the state subsides and the problem becomes one of 'too much law'. New forms of interaction on a global scale and the emergence or expansion of transnational normative orders, some related to the sovereign state (e.g. the EU) and some not (e.g. lex mercatoria), coexist on the same level of authority and create numerous puzzles of normative coordination.

There is, of course, a wide and ever expanding range of ways of thinking about legal pluralism. Without meaning to provide a survey of such theories here, ${ }^{2}$ let me classify them under three broad archetypical headings.

1. I refer to 'early modernity' not chronologically but substantively and with specific focus on the political and the emergence of states. I regard this as capturing colonial and post-colonial contexts.

2. For such surveys see indicatively B.Z. Tamanaha, 'Understanding Lega Pluralism: Past to Present, Local to Global', 30 Sydney Law Review 3, at 375-411 (2008). 
First, there are sociological and anthropological accounts of legal pluralism. These focus on observing and recording the ways in which various communities of people are governed by practices of rule-following. There is a long tradition of such studies of legal pluralism and they have taught us a great deal about the richness of the nomic world. The approach, however, has a serious limitation (though perhaps not everyone considers it to be a limitation). A collection of observations of phenomena of governance does not amount to a theory of law, pluralist or otherwise. And such a foundational theory is in fact prior to and always underlies and to some extent guides sociological or anthropological observation. ${ }^{3}$

The second, and more recent, approach to legal pluralism focuses on the proliferation of legal institutions and the problem of coordination of various sources of authority. ${ }^{4}$ The main question here is how to make sense of the fact that, in a new environment of globalised communication and interaction, we are subject to a variety of legal orders (transnational law, international law, customary cross-boundary law and so forth). In subscribing to a specific institutional conception of law this theoretical approach is at least clear as to what needs coordinating and it is therefore better placed to suggest ways of reducing the complexity of the legal universe. But this is at the same time its limitation. Manifestations of legality, which do not meet this particular description of institutions, will fall through the cracks of the theory.

A third way of trying to make sense of legal pluralism is to work out a conception of law, which will be inclusive of as many possible manifestations of law as possible and, at the same time, capable of determining what the object of enquiry is. I have advanced such an approach to the question of legal pluralism elsewhere, and I still find it plausible and useful as a way of understanding law generally and legal pluralism in particular. ${ }^{5}$ However, there is still something important that needs to be explored, and this is whether this take on law and legal pluralism is in a position to account for the possibility of normative coordination of dispersed legal orders without overdetermining the content of law and thus undermining the pluralist character of the theory. ${ }^{6}$ What I want to do in this article is explore whether the theory of legal pluralism that I have been defending can establish the possibility of normative communication

3. There is a wealth of studies of this kind. An important publishing outlet for anthropological legal pluralist work is The Journal of Legal Pluralism and Unofficial Law.

4. Some examples of this approach to legal pluralism include: N. Walker 'The Idea of Constitutional Pluralism', 65 Modern Law Review 3, at 317-359 (2002); N. Krisch, Beyond Constitutionalism the Pluralist Structure of Postnational Law (2011); P.S. Berman, Global Legal Pluralism: A Jurisprudence of Law Beyond Borders (2012).

5. E. Melissaris, Ubiquitous Law: Legal Theory and the Space for Legal Pluralism (2009).

6. Klaus Günther has attempted to address this issue by appealing to a meta-law, which will include certain fundamental rights. K. Günther, 'Rechtspluralismus und universaler Code der Legalität: Globalisierung als rechtstheoretisches Problem', in L. Wingert and K. Günther (eds.), Die öffentlichkeit der Vernunft und die Vernunft der öffentlichkeit (2001), at 539 . between legal orders without prejudicing the outcome of this communication.

For the sake of simplicity I will refer to this specific take on law and legal pluralism as 'legal pluralist theory' - without of course implying that it is the only possible way of making sense of legal pluralism - and I will generally refer to the fact of legal pluralism as 'legal pluralism'. I will begin by unpacking the basic tenets of the theory and then explore its implications.

2.1 Why a Conception of Law?

Legal pluralist theory takes on board the observations of those who record the apparent intertwining or clashes of what seem to be distinct legal orders as prima facie evidence that law is not necessarily reduced to the state. It also takes seriously the intuition that such clashes are due to law's situatedness in time and space. But it also acknowledges that if these observations are to be accompanied by the stronger claim that the fact of legal pluralism is distinctive and irreducible to value pluralism or institutional pluralism and that it complicates the normative universe in a novel way, more has to be done than simply recording the phenomenology of either of the two manifestations of legal pluralism. Legal pluralist theory therefore takes a step back. It asks what the analytical conditions of legal pluralism and what the necessary entailments of law's situatedness are. And, in a move that dissatisfies those who find it impossible to overcome the mental block of necessarily associating law with the state, these questions are cast as an enquiry into the concept of lam tentatively so called, an enquiry into the legal character of various actually existing normative orders. It is only by clarifying the conditions of existence of the legal that it will be possible to work out precisely why legal pluralism raises a challenge to our current understanding of law and why legal pluralism cannot be shrugged off as a type of pluralism that can be negotiated and reduced within state law.

To understand why this is important, consider the following. Mainstream, monist legal theories generally hold law's special character as perhaps framing the question of legitimacy but not as necessary to it. This holds both for those who dissociate the question of law's validity from law's legitimacy and for those who link them as a matter of necessity. They both consider state law as uniquely capable of serving social integration by incorporating and enforcing values, which are acceptable - on whichever grounds - by all. For instance, empiricist legal positivism of the Benthamite-Hartian tradition may acknowledge value pluralism. ${ }^{7}$ It may also accept - although no legal positivist explicitly does so legal pluralism in its weak sense, as it does not rule out the existence of legal orders, which do not share all the

7. J. Bentham, Of Laws in General, edited by H.L.A. Hart (1970); H.L.A. Hart, The Concept of Law, 2nd edn (1994). The same goes for political theories, which try to deal with value pluralism and, in one way or another, espouse the positivist conception of law. For Rawls, for example, everything becomes visible once participants have exited the Original Position. Therefore the law of the state structures normative commitments, which are perfectly visible from all perspectives. See J. Rawls, Political Liberalism (1993). 
characteristics of the focal case of state law. But it is not prepared to accept legal pluralism in the stronger sense, because it considers the conditions of existence of these legal orders to be visible from any perspective. The legal universe is transparent for Hart and the term 'law' has no substantive implications in relation to the question of how these legal orders may be coordinated. For natural law theories in all their variants ${ }^{8}$ things are even more straightforward, as they do not acknowledge either value pluralism or legal pluralism other than as a plurality of mistaken beliefs.

Therefore, all mainstream legal theories could readily argue that, even if some communities of people maintain their own normative practices, the question is whether these regimes are compatible with the values that apply to all and that animate central, state law. If so, they can be treated as qualified exceptions, but the crucial point is that they will still be sanctioned by central, state law. To rebut this objection, legal pluralist theory must show that there is something in the character of these normative orders that complicates in a novel way the legitimacy discourse. It is this character that legal pluralist theory terms as 'legal' and tries to tease out.

There is an assumption implicit in this foundational thesis concerning the aims of legal theory generally. Legal pluralist theory is premised on the view that the end point of every enquiry into the legal is practical. ${ }^{9}$ What is ultimately at stake is to work out the conditions under which large, and diverse, groups of people in the here and now can coexist by governing their affairs in a way that is acceptable by all. For this to be possible, nothing should be excluded from the discourse of legitimacy conceptually from the very outset. The label 'law' has significant consequences for the lives of those who are born in a society governed by law and who often do not consciously choose to be subject to legal obligations, obligations that are purportedly justifiably enforced precisely because they are legal. Therefore, hastily reserving 'law' exclusively for state-centred normative orders, maintaining categories that emerged as a result of the political domination of the state and still ascribing normative significance to such distinctions potentially (whether this is in fact the case can only be ascertained at the end of the enquiry) obscures matters and distorts the legitimation process.

\subsection{What Kind of Conception of Law?}

In order to show that there is something in the legal quality of a normative order that has an effect on the question of legitimacy, legal pluralist theory must produce a conception of law. Such a conception is not in any way independent of our actual practices and experiences. Indeed, it would be inconsistent for it to be so, because of the very starting hypothesis of legal pluralist

8. See characteristically J.M. Finnis, Natural Law and Natural Rights, 2nd edn (2011); R. Dworkin, Justice for Hedgehogs (2011).

9. This is not to say that every single enquiry into the legal is practical. Description is possible and, indeed, necessary. However, even accurate description of our normative practices is at best incomplete if it does not service the practical discussion of legitimacy. theory, namely that there is something about the social situatedness of law that accounts for the incompatibility between its different instances. At the same time, it is not bound to local contexts. But the requirement of immanence does not mean that it is impossible to formulate an abstract conception of law with some degree of generality. One may do this by abstracting from observable manifestations of social normativity and by singling out some characteristics that appear to be uncontroversial and shared across instances of social normativity. I consider this to be a by and large constructivist conception of law.

The legal pluralist conception of law must be able plausibly to capture legal pluralism. It should therefore be stripped of historical contingencies - such as attachment to certain sources - so as to encompass as wide a range as possible of phenomena of social normativity, which appear to display the same basic characteristics despite their differences in the trimmings.

The constructivist and highly general and abstract nature of this conception of law has certain important features:

i. It is inevitably minimalist. If we discount contingent historical factors, it is very few commonalities that it will be possible to single out.

ii. It raises the interconnected claims to formality and neutrality. That it is formal does not mean that it is not historically indexed. In other words, it is not to say that the legal pluralist conception of law claims that it is possible to draw the framework of legality in an a-contextual way. In that sense it is not neutral because it could be otherwise in radically different contexts. But it is neutral in the more salient sense of drawing law's outer boundaries in a way that will not determine law's content. In fact, not remaining neutral is not an option for legal pluralist theory. This follows from the presuppositions of engaging in enquiry into the conditions of law in the first place. Taking an interest in the regulatory regimes of others already presupposes that the observer holds the group under observation as capable of setting, applying and following rules to govern their coexistence and that they are not prey to coercion or other external (or internal but unmediated by reason) pressures, over which they cannot exercise any control. Recognising this capacity to respond to rules has a central practical consequence: it obligates the enquirer to form her enquiry in a way that will not usurp or undermine that capacity of the groups under observation. And the only way of doing so is by starting from as thin a sense of law as possible, without furnishing it with any content.

Some doubt that it is even possible to formulate a formal and neutral account of law and, even if it is possible, they argue that it is of no merit. Both these objections are backed by the argument that law is all about reasons, and therefore as soon as you speak about law you already select a set of rea- 
sons for which to have law, to have a specific type of law and so forth. ${ }^{10} \mathrm{I}$ do not want to rekindle this discussion here, but it is worth saying two things. First, legal pluralist theory does not have to deal with the question of whether it is possible to give a neutral account of reasons for action because at the stage of observation it does not even ask what these reasons are. ${ }^{11}$ And giving a purely formal account of the observable manifestations of actual normative practices seems perfectly possible precisely because they are actual social practices. ${ }^{12}$ So there will of course be reasons backing practices of social rule-following by situated agents, but one does not have to consider these reasons simply to say that law manifests itself as social rule-following by situated agents.

Is such a formal account of law of any merit? One might think that it is not only if one believes that legal reasons do not depend in any may on the attitudes of those who act on them. One might think that the way in which a community of people holds reasons to apply to them is perfectly visible from the observer's standpoint because there can be no contingent variations in our beliefs about how reasons apply. Or one might think, as many do, that how reasons in fact apply to us and therefore what makes for good or bad law, has nothing to do with our beliefs at all and is instead a matter of transcendental truth. Legal pluralist theory, of course, does not have to accept either of these views. The former is mistaken because beliefs are context-sensitive and therefore at least potentially opaque. The latter because the starting hypothesis of legal pluralist theory is precisely that there is something about the situatedness of law, which frames the legitimation process differently. And should this hypothesis be proven right, then, as I shall show later, it will have to be accepted even by those who think of reasons as agent- or context-independent.

10. See characteristically J.M. Finnis, 'Law and What I Truly Should Decide', 48 American Journal of Jurisprudence, at 107 (2003); R. Dworkin, 'Hart's Postscript and the Character of Legal Philosophy', 24 Oxford Journal of Legal Studies 1, at 1 (2004). For a comprehensive response see A. Marmor, 'Legal Positivism: Still Descriptive and Morally Neutral', 26 Oxford Journal of Legal Studies 4, at 683 (2006).

11. Incidentally, it seems to me to be plainly wrong to say that it is impossible for one to describe the actions of others as well as the reasons that justify these actions without one endorsing these reasons. Imagine, for example, that the Dworkinian Judge Hercules or the Finnisian perfectly enlightened moral/legal person gives you, an outsider, an account of their law and the reasons behind it. Reproducing that account accurately by substituting the first person singular with the third person (e.g. 'Judge Hercules believes [...]') is quite obviously possible and neutral. Now, absent such idealisations in the real world, it will clearly be more difficult to select the set of reasons that all participants would agree animate the point of their practice, but this is not to say that it is impossible.

12. Dworkin questions this and argues that law should be considered an 'integrated' value alongside liberty, equality and the like. This, however, is to disregard that law is necessarily something that groups of people do; it is a practice that can be described prior to and independently of considering the normative meaning that the participants in the practice ascribe to it. See Dworkin (2004), above n. 10 iii. Legal pluralist theory of law is fully aware of the falsifiability of its conception of law. Uncontroversial as the formal generalisation of our practices may appear prima facie, it cannot be precluded that it may fail to capture phenomena that seem to be doing the same kind of work in social life. If so, then it must be revised so as to improve its explanatory potential. Whether this is the case cannot be revealed before beginning to apply the formal conception of law to specific contexts. And, as I shall show a little later in this article, this application can only happen by substantively engaging with other legal communities.

iv. The scope of what counts as law is drawn rather wide. Legal pluralist theory does not discriminate a priori between what we customarily refer to as 'law', by and large state law, and other social normative orders. Legal pluralist theory thus departs from mainstream legal theory, which in one way or another relies heavily on the assumption that the term law is reserved for the normative order sanctioned by the modern state. It also puts to the test the resulting distinctions between normative orders, which bracket off everything that does not stem from the state as 'social', 'associational' and so on conceptual rather than substantive grounds. Some may regard the conflation of such conventionally established distinctions as unnecessarily revisionist. ${ }^{13}$ Contrary to this, I consider it to be a significant virtue of legal pluralist theory. This is because, as I argued earlier, nothing should be excluded from the outset on conceptual grounds. It is only if we begin wide that we will be able to see the parameters of the legitimacy discourse.

\subsection{Which Conception of Law?}

So far I have outlined why it is necessary for a legal pluralist theory to proceed on the basis of some conception of law and the general features of such a conception. I will now begin to outline its content.

\subsubsection{Lam, Social Acceptance, Reasons}

I consider it uncontroversial that in its manifestations law can be described as an instance of collectiverule-following by temporally and spatially situated agents. By rule-following I do not necessarily mean that law necessarily fits the mould of what we are familiar with in constituted, congruent legal systems, i.e. a system of inscribed rules stemming from identifiable sources. What I mean is that law necessarily consists in ought-propositions, which are external to each agent and require the exercise of agents' will for their application. Therefore, law will always be at least translatable as such ought-

13. Simon Roberts has forcefully argued against this conflation of conventional categories. See S. Roberts, 'After Government? On Representing Law Without the State', 68 Modern Law Review 1, at 1 (2005); S. Roberts, 'Against Legal Pluralism', 42 Journal of Legal Pluralism and Unofficial Law, at 95 (1998) 
propositions, even when it is manifested differently, e.g. as symbols or artefacts. ${ }^{14}$

I take it that this much is immediately obvious even on a quick observation of our practices of law, and this is why I take it to be uncontested. What may be contested is whether rules have the capacity to guide our actions at all. Some doubt that they do, and so they invite us to revisit our whole understanding of normativity. They may well be right. It may be the case that certain facts in the world trigger some physiological reaction in us, which explains the convergence of our patterns of behaviour. Nevertheless, what is crucial for our understanding of lam is that we experience law as a set of rules establishing obligations and we judge our acts as conforming or not with law's dictates. It is this way in which law is inscribed in our consciousness that I take to be uncontroversial and that I consider the central concern of legal theory, i.e. the attempt at grasping our normative practices. ${ }^{15}$

Since law is a rule-following practice, it clearly consists in more than just coercing people to act in a certain way. Law must be capable of guiding people's actions; it must be such that people are given the opportunity to follow it. This entails that law must be capable of generating obligations on the part of its addressees. On the surface level, this has to do with what many have pointed out, namely that law must make demands of people, which can be properly met only by exercising one's will, and which are expressed in, or translatable into, normative language, which is the language of obligation. ${ }^{16}$ There is hardly any need to say more on this at this stage, although a little later I will return to another central entailment of the requirement of law being capable of guiding its addressees' actions.

Now, law being capable of generating obligations does not suffice. It must in fact generate obligations. What does this mean? The question is generally posed as a dilemma between social and justified normativity. On the former view, law's normativity depends on the acceptance on the part of its addressees as binding. According to the latter view, legal obligation is agentindependent. We are under genuine legal obligations only to the extent that there are good and belief-independent reasons, including reasons for having law in the first place, grounding these obligations.

Both these views conflate two separate questions. On the one hand, there is the question of what accounts for the very possibility of normativity. On the other hand, there is the question of the conditions of existence of law. Once we disambiguate these two questions, we will see that both the social acceptance and the reasondependence views are correct but on different levels.
For there to be lam the participants in a legal practice must have accepted it as generating obligations. This is because of law's character as social rule-following by situated agents. For there to be a legal order, therefore, a normative order that has an impact on participants' lives by structuring their normative expectations, the beliefs of those participants regarding the normative status of law must converge. But this does not necessarily amount to saying that generalised beliefs regarding the normative force of law suffice for law to generate any true obligations. In other words, to say that for there to be law there must be a convergence of beliefs is to say something about the necessary sociological conditions of existence of law and not about the nature of normativity. One might therefore question, as natural lawyers and others typically do, whether our psychological attitudes can generate obligations. One might argue that people might hold mistaken beliefs and consider themselves to be under obligations, which are not true because they do not comply with some prior and agent-independent obligations derivable from and/or accessible by reason. But even those holding that view must accept that in order for there to be lam - and it is worth emphasising the social practice character of law once again - its addressees must accept those 'true' obligations as binding. In other words, whether an obligation is genuine or not by some extra-legal standard does not have to do with whether it is a legal obligation. 'True' obligations can become legal only if they are so recognised and accepted. $^{17}$

None of this is to suggest that law must be efficacious or substantively accepted and legitimate, in order for it to be law at all. What I mean by social acceptance is only the sense of recognition, on the part of its addressees, of the law's binding nature. Law will be efficacious only if its subjects in fact, and for whatever reason, act in the way that law expects them to. The requirement of social acceptance qua recognition is also different to law's legitimacy understood as actual acceptance or as acceptability. One might think that the law is legitimate to the extent that its addressees are motivated or compelled by the same reasons, which ground the law. ${ }^{18}$ But recognising law as binding does not entail endorsing it in that way. Therefore, social acceptance of law as binding guarantees neither the law's efficacy nor its legitimacy. It is, however, entailed by, and is therefore a threshold condition for, both efficacy ${ }^{19}$ and legitimacy qua acceptability.

This already takes us to the reason-dependent view of law's normativity. Although general belief convergence is necessary for there to be law, viewed from the stand-
14. For an argument to the contrary, although with special reference to religion, see S.N. Balagangadhara, 'The Heathen in His Blindness ...': Asia, the West, and the Dynamic of Religion (2005).

15. Alain Supiot forcefully, and I think convincingly, displays the dangers in not fully recognising this nature of law in Homo Juridicus: On the Anthropological Function of the Law (2007).

16. See Hart's account in The Concept of Law, above n. 7 .
17. This objection is customarily raised against Hart. It is justified to do so because Hart did not clearly differentiate between the two questions that I single out here and tended to conflate the question of the conditions of existence of law with the nature and sources of normativity.

18. Clearly, law may be efficacious, say due to the ferocity of its enforcement, but still not be legitimate.

19. I mean efficacy as law. If, say, the addressees of law simply happen to act in the way that the law requires them to, then it cannot properly be said that that law is effective as law. 
point of each participant, law is not merely accepted in that thin manner. It is accepted as binding on the basis of reasons; reasons for having lam, for having a specific type of law and for the law having specific content. To illustrate the difference between the participant accepting the law on the basis of reasons and the fact of recognition/acceptance, consider this: Say A has good reasons to $\varphi$. This does not entail that A accepts a rule according to which 'you ought to $\varphi$ ' as binding. But if A does accept that rule as binding, then A will be doing so on the basis of reasons and not unreflectively. Not all participants will always consciously employ these reasons, but, when pressed to reflect on the matter, they will only be able to explain legal obligation on the basis of reasons. They may also not all accept law for the same reasons. Note, however, once again that the convergence on the same reasons does not have to do with whether there is law but with whether the law is legitimate or stable. If the reasons grounding the law are rationally and reasonably acceptable by its addressees in abstracto, then the law will count as legitimate. If they are acceptable and accepted in concreto, i.e. in light of actual conditions in the legal community, then the law will also be stable in the long run.

\subsubsection{The Fustification Requirement}

The fact that law is not about sheer coercion or mere physical responses to stimuli unmediated by reason entails that law's addressees are capable of following rules, which prioritise certain reasons for action over others. This in turn means that law's addressees are capable of responding to reasons, of hierarchising them and of being motivated by them. And given that law is an instance of social rule-following, the same assumption holds for everyone who is a participant in the practice of law.

These presuppositions have one important implication for the attitudes of participants in law. When one purports to be saying anything in law or, to phrase it differently, when one makes a legal judgment in any context either institutional or not, one simultaneously claims that one's addressees, i.e. the rest of the participants in law, recognise that judgment as potentially binding and as containing reasons to which they can respond. To raise such a claim means to be able to defend it, and to defend normative claims means to justify them. And the social character of law, which, as I have argued, means that the participants' attitude is central to the existence of law, entails that the claim is raised to the potential participants in that manifestation of the legal. ${ }^{20}$

The fact that law is backed by reasons and that claims in law are always claims to the best possible reasons and are potentially addressed to all participants in law does not necessarily entail that one is under a duty to provide

20. Who the potential participants are depends largely on actual contexts. Clearly, in the real world, some jurisdictional division will be required, which will place reasonable constraints to the scope of legal claims. But how jurisdiction is to be set is a substantive matter, which cannot be settled by the concept of law alone but can only be deferred to the stage of its application. such reasons and to defend them to others. Some, like natural lawyers and interpretivists, believe that legal reasons are agent-independent and that whether one appreciates them or not has nothing to do with whether they apply to one. For those holding this view there may be other reasons for giving full justificatory accounts, say stability or transparency, but these reasons are entirely contingent. ${ }^{21}$ In what follows I will show that under a pluralist conception of law, one is always expected to publicly defend such reasons. But first I must make the argument for law's relative closure.

\subsubsection{Normative Intelligibility and the Possibility of Legal Pluralism}

So far I have argued that for there to be law, i.e. social rules that govern groups of people in real contexts in space and time, these rules must be regarded as binding by the people. Whether these obligations are genuine according to some substantive theory of morality is secondary in relation to the question whether there is law in the sense that without acceptance there can be no law even if there are good reasons applying to agents. But for law to be normatively accepted, it must be normatively intelligible, it must purport to guide participants' actions in a way that they can make sense of.

Since social acceptance is necessary for its existence, law is normatively intelligible only to the extent that it taps into beliefs shared by its addressees regarding the possible normative meaning of the world. ${ }^{22}$ Law requires a commonly recognised terrain of normative possibility, which is determined by people's normative perceptions of the world, such as their normative perceptions of time, space and connections between events. It requires a background of shared perceptions of how the world may be changed through their normative commitments. Given that it addresses temporally and spatially situated agents, law's normative intelligibility must rest on the merging of the practical and the theoretical manifesting itself as implicitly or explicitly shared beliefs - what I have elsewhere called shared normative experiences. ${ }^{23}$ We should be careful here not to confuse this with a fully fledged naturalistic thesis regarding reasons or other possible understandings of the relationship between fact and norm. That participants in law must hold such beliefs for there to be law is not to say that facts in the world actually have inherent normative meaning. Neither is it tantamount to the self-evident fact that norms are applied to facts and that there must be some rough epistemological consensus as to the meaning of these facts, in order for norm-application to be largely uncontroversially possible and stable. Nor is normative intelligibility the same as the scope of applicability of norms

21. This seems to be Dworkin's take on democracy. See R. Dworkin, Is Democracy Possible Here? Principles for a New Political Debate (2006). For a critique consistent with the argument in this article, see $\mathrm{E}$. Melissaris, 'A Social and Legal Theory of Re-enchantment: Interpretivism, Argumentation, and the Law', 19 Constellations 4, at 609 (2012).

22. My argument here is a variation on a theme. See particularly R. Cover, 'Nomos and Narrative', 97 Harvard Law Review, at 4 (1983-1984); Supiot, above n. 15

23. Melissaris (2009), above n. 5. 
or the genuine content of values. In order for participants in a legal community to meaningfully disagree on such matters of application they must already share a horizon of normative possibility, which determines what is normatively imaginable and what is not.

Very importantly, how these beliefs are generated and evolve depends on their actual context. Precisely because they are beliefs about the normative significance of the world for participants' coexistence, they are not static but dynamic and constantly changeable. They may be tacitly transformed through the ways in which social relations and collective relations between participants and the environment change with time. They may also be determined and change self-reflexively. The consolidation of some of them as a set of rules of binding force may create a coherent system, which is relatively closed and sets the criteria of normative possibility, thus accordingly shaping participants' beliefs. This, however, is not to say that shared normative experiences are exclusively systemically determined and that they cannot be put to the test by those who hold them. Like all beliefs it is possible for one to question them in light of new information and through processes of self-reflection.

Highlighting the fact that law relies on such jurisgenerative $^{24}$ commitments does not give the latter any specific content. This content will vary depending on the context of emergence and development of shared normative experiences and the type of law that they enable. Therefore a full understanding of these particular conditions of legality can only be formed from the perspective of the participants and their self-understanding of their practices. This is what accounts for law's potential autonomy and relative closure, which has at least two important aspects. First, from the perspective of the observer and without the experience and understanding of the terrain of normative intelligibility, one cannot make full sense of legal rule-following as such. It follows that one will not be able to know with certainty all the manifestations of legality available out there. Secondly, one can be a participant in an instance of such social/ legal rule-following only if and to the extent that one already partakes in this communal understanding of the normative meaning of the world.

This does not mean that law becomes an impenetrable system inaccessible by others. To be sure, non-participants will not be in a position to endorse participants' shared normative experiences, because they do not form part of their belief system. But shared normative experiences can be explained and communicated by participants to non-participants in a way that the latter can form some understanding of the insiders' perspective. Such communication can, especially given the revisability of normative experiences, trigger a process of selfreflection by both parties, which may then, given the right conditions, lead to a mutual understanding and convergence or mutual acceptance.
So a new conception of law's facticity emerges, and along with it the possibility of legal pluralism is revealed. The differentia specifica of law ceases to be its association with a source or the rightness of its content in compliance to some transcendental moral order but rather its dependence on the way that the participants in it make sense of the world in its normative meaning. Since this experience is bound to the context law can emerge in any context in which normative social relations emerge. The dynamic nature and multivariation of these contexts account for the immense complexity and untidiness of the legal universe. For instance, although in some of its manifestations law will be systematised in an arguably coherent whole, that is the conception of law with which we are more familiar, in others it will not be so. And, although we can never be outside law, it is perfectly possible that we are subject to different instances. The same agent may find herself participating in a, unique to her, variety of legal orders.

Does all this mean that legal pluralism in its stronger sense, not only the existence of social normative orders independently of the state - for which patterns of social acceptance can provide an indication - but the existence of closed non-state social normative orders, is a fact? Not necessarily. But its possibility cannot be ruled out $a$ priori. One cannot know from a philosophical or an observer's empirical perspective whether one deals with normative experiences, which one does not share, whether one oversteps one's own terrain of normative intelligibility or trying to impose as binding onto others something that they find unintelligible. But, as I shall argue in the following section, the very character of law allows for some communication between legal orders.

\section{Reducing Legal Pluralism}

The wheel is about to come full circle, but let us take stock before moving on. I have argued so far that the idea of law itself, as an instance of collective rule-following by temporally and spatially situated agents, entails the following: first, each time one claims to be making a legal utterance, one claims that all the participants in law are capable of being bound by it, in fact bound by it and capable of being motivated by it (though not necessarily are in fact). Secondly, law consists in shared normative experiences, which make it normatively intelligible to start with. Thirdly, that law projecting itself against the background of normative intelligibility accounts for legal pluralism both in the sense that law is not necessarily bound to the state but may emerge in any context as well as in the sense that these instances of law are potentially closed and invisible to the observer. I should also note again that my focus is on complex, differentiated societies, in which integration through rule-following is not possible on the basis of personal recognition and communication. In such contexts diverse legal orders encounter each other constantly and in a variety of unpredictable ways. This untidiness of 
the modern legal universe makes it imperative that we think carefully about the possibility of meaningful communication between such legal orders.

What I have argued so far has several ramifications. Centrally, every attempt at law-making must be based on justification, that is the giving of clear and openly available reasons. Now, one who regards law as subordinate to transcendental, agent-independent reasons would leave it at that and not require anything else for law to indeed be law. But recognising the possibility of legal pluralism forces one not only to be prepared to justify legal claims on the basis of reasons but also to ensure that all those potentially affected will have the opportunity from their perspective to assess the intelligibility of how they are required to act and to be able to voice their disagreement. Otherwise, one runs the risk of failing to do law altogether, because one would be expecting others to follow rules, which they are not in a position to follow. So, to make the same point from a different angle, all attempts at making law must first deal with the risk of legal pluralism.

The conditions of normative intelligibility can be clarified and communicated across standpoints only through dialogue, which I have elsewhere termed interperspectival. ${ }^{25}$ And the more complex the nexus of beliefs forming and surrounding the terrain of normative intelligibility, the more far-reaching that dialogue must be. Does all this have any substantive ramifications, though? Or is it the case that one can do law by simply asking all those in the sphere of validity of law to tick boxes in a sociological survey stating whether what that law requires of them is intelligible or not?

As I have said, from the first-person singular, law is not simply a matter of neutral acceptance but a matter of responding to reasons. Once within the practice of law, questions regarding the law are necessarily practical, not theoretical. Therefore, when a participant, i.e. someone who is expected to abide by the law, is asked whether a certain legal regulation is normatively intelligible, she is not simply asked whether that regulation coheres with her belief systems. She is asked whether she can endorse that regulation and its justification, whether it coheres with her normative commitments, the reasons on which she is inclined to act. To illustrate, the question is not only 'does the obligation to $\varphi$ make sense to you?' but also 'ought you to $\varphi$ ?'.

Before concluding I should emphasise two things. It is not unthinkable that at a given moment in the history of a legal order, there may be law in the sense that it will be fully normatively intelligible to all and so forth, without this law having gone through the stage of deliberative exchange of reasons and arguments. It could well so happen that it all serendipitously falls into place. However, when one, or a group of people, claim to make lam, when they make specifically legal claims, which are meant to apply to others than just them, then they are bound by the entailments of what it means to do law. This is a moral duty, which follows from engaging in a practical activity of a certain kind. Seen from the perspective of law's addressees, absent procedures of public justification, they cannot be held to be under any duty stemming from law. Secondly, none of this establishes a duty to govern by law. This is because my analysis is not premised on some metaphysical truth regarding rights or duties that we may have prior to our actual practices, but is heavily historically indexed. It is a construction of the entailed requirements of in fact engaging in social rule-following practices: if we are to be governed by law, what will that entail?

The upshot of this is that the dialogue on normative intelligibility and the alignment of normative experiences, which is necessary for ascertaining whether law is possible at all, is at the same stroke transformed into a dialogue on legitimacy, that is on the substantive acceptability of public norms. Bringing all this together, it follows that in order to have law, such procedures must be in place as to guarantee the exchange of views on reasons, which everyone is prepared to accept. This is already to establish that no law can be made without the inclusion of all those who potentially participate in that law. In other words, it is to establish a necessary link between law and public justification and the general idea that norm-determination, and this includes the norms setting up the institutional procedural framework of collective deliberation, must proceed on the basis of the involvement of everyone affected by those norms.

My conclusion may not satisfy those who wish the idea of law itself to provide thicker normative assurances against attacks on human dignity, rights and so forth. I am sceptical as to whether the concept of law alone can offer such assurance. But it is also not as fragile as some may fear. It can guarantee transparency and publicity and open up the space for political deliberation. It also protects from outright coercion and ensures inclusiveness. And note that the requirement of public justification also has some further entailments, such as some minimum requirements of the rule of law, but I cannot outline these in this context. But this is where the theory of legal pluralism, in reality a general theory of law, reaches its limit. It must then hand over to political theory, which will work out the conditions of implementation of this foundational idea and furnish it with substantive principles in actual contexts. 